\title{
Educação do campo e a prática social: uma oficina pedagógica transformadora sobre a moringa oleiffera
}

Este artigo discorre sobre a educação formal do campo vinculada ao mundo do trabalho e a prática social dos educandos, a partir de uma oficina pedagógica realizada com turma de um curso técnico em agropecuária. Como ponto de partida se emprega os estudos a respeito da moringa oleífera devido a sua vasta aplicação cotidiana nas diversas áreas do conhecimento, e por ser uma planta presente na região, além de seu potencial de contribuição para a comunidade local dos discentes, evidenciando assim três elementos importantes nos aspectos didáticos-pedagógicos para uma educação emancipadora: a interdisciplinaridade, a contextualização e a transformação da realidade. A metodologia utilizada foi através da aplicação de uma oficina intitulada "As diferentes utilidades da Moringa Oleífera", por meio de observações sobre a atividade e as respostas referentes a um questionário empregado no final das ações. Os objetivos principais foram vincular a educação formal com a prática social dos educandos do campo, socializar conhecimentos contextualizados sobre as diferentes utilidades da moringa, contribuir na formação técnica e social dos alunos do Centro Territorial de Educação Profissional do Piemonte Norte do Itapicuru (CETEP) e ampliar os saberes e a experiência profissional em sala de aula para os licenciados em Ciências Agrárias. O resultado da oficina aponta para a efetivação de um ensino contextualizado interdisciplinar, vinculado aos aspectos do mundo do trabalho e das práticas sociais, pautado na demanda de uma educação do campo. Ressalta-se especialmente o valor didático-pedagógico dessa atividade para todos os alunos que participaram, demonstrando interesse em compartilhar os saberes adquiridos, cooperando assim com sua comunidade, na expectativa de uma melhoria na qualidade de vida dos pequenos produtores rurais da região.

Palavras-chave: Educação do campo; Prática social; Moringa oleífera.

\section{Field education and social practice: a transforming pedagogical workshop on moringa oleifera}

This article discusses the formal education of the field linked to the world of work and the social practice of students, from a pedagogical workshop held with a class in a technical course in agriculture. As a starting point, studies on the oil moringa are used due to its wide daily application in different areas of knowledge, and because it is a plant present in the region, in addition to its potential to contribute to the local community of students, thus evidencing three important elements in the didactic-pedagogical aspects for an emancipatory education: interdisciplinarity, contextualization and the transformation of reality. The methodology used was through the application of a workshop entitled "The different utilities of Moringa Oleifera", through observations on the activity and the answers referring to a questionnaire used at the end of the actions. The main objectives were to link formal education with the social practice of rural students, to socialize contextualized knowledge about the different uses of moringa, to contribute to the technical and social training of students at the Territorial Center for Professional Education of Piemonte Norte do Itapicuru (CETEP) and expand knowledge and professional experience in the classroom for graduates in Agricultural Sciences. The result of the workshop points to the implementation of contextualized, interdisciplinary teaching, linked to aspects of the world of work and socia practices, based on the demand for rural education. The didactic-pedagogical value of this activity is particularly noteworthy for all students who participated, showing an interest in sharing the knowledge acquired, thus cooperating with their community, in the hope of improving the quality of life of small rural producers in the region.

Keywords: Countryside education; Social practice; Moringa oleífera.

Topic: Políticas Sociais

Reviewed anonymously in the process of blind peer.

Bianca Oliveira de Souza (iD

Instituto Federal Baiano, Brasil

http://lattes.cnpq.br/7927737040435819

http://orcid.org/0000-0002-7110-0864

bia001984@gmail.com

Thales de Araújo Barboza (iD

Instituto Federal Baiano, Brasil

http://lattes.cnpq.br/8698378042799790

http://orcid.org/0000-0001-7093-6179

thales.ba.tb@gmail.com

Yane Gama da Silva

Instituto Federal Baiano, Brasil

http://lattes.cnpq.br/6287071164744153

http://orcid.org/0000-0001-7905-5036

yanegama21@gmail.com
Received: 11/12/2019

Approved: 24/03/2020

\author{
Wesley da Silva (iD \\ Instituto Federal Baiano, Brasil \\ http://lattes.cnpq.br/5877898545818933 \\ http://orcid.org/0000-0002-6843-9576 \\ silvaws1998@gmail.com \\ Marcos Oliveira Santos (iD) \\ Instituto Federal Baiano, Brasil \\ http://lattes.cnpq.br/3608399669010480 \\ http://orcid.org/0000-0001-9825-0478 \\ marcosoliveiraccb@gmail.com
}

Referencing this:

SOUZA, B. O.; BARBOZA, T. A.; SILVA, Y. G.; SILVA, W.; SANTOS, M. O. Educação do campo e a prática social: uma oficina pedagógica transformadora sobre a moringa oleífera. Social Evolution, v.4, n.1, p.10-18, 2020. DOI: http://doi.org/10.6008/CBPC2595430X.2020.001.0002 


\section{INTRODUÇÃO}

A educação é um direito fundamental do cidadão e dever do Estado e da família, com decisivo papel social na formação humana, cidadã, técnica e tecnológica, conforme apregoa a Constituição Federal de 1988 (CF 1988) em seu artigo 205 e a Lei de Diretrizes e Base da Educação Nacional (LDBEN 9.394/96) no artigo 2o. Em se tratando de educação do campo, tais pressupostos legais não foram assegurados pelo poder público por muitos anos, até que reivindicações de movimentos sociais tenham colocado a oferta de educação formal para a população campesina nas pautas das políticas educacionais a partir da segunda metade do século XX em âmbito mundial.

Abordando o princípio constitucional da vinculação entre educação escolar, o trabalho e as práticas sociais, o presente trabalho trata sobre uma oficina realizada por discentes do curso de Licenciatura em Ciências Agrárias do Instituto Federal Baiano campus Senhor do Bonfim. A oficina intitulada "As diferentes utilidades da Moringa Oleífera" foram desenvolvidas com alunos do curso técnico em agropecuária no Centro Territorial de Educação Profissional do Piemonte Norte do Itapicuru - CETEP que fica localizado em Jaguarari - Bahia no ano letivo de 2018.

O tema proposto surge da necessidade de se promover uma educação ampla, interdisciplinar ${ }^{1} \mathrm{e}$ contextual a partir da disseminação de conhecimentos sobre as utilidades da moringa, tendo em vista a presença significativa dessa planta na região e sua vasta aplicação nas diversas áreas da atividade humana. Assim, os objetivos principais da aplicação dessa oficina foram vincular educação formal com a prática social de educandos do campo, socializar conhecimentos contextualizados sobre as diferentes utilidades da moringa, contribuir na formação técnica e social dos alunos do CETEP e ampliar os saberes e a experiência profissional em sala de aula para os licenciados em Ciências Agrárias.

Para tanto, metodologicamente, na aplicação da oficina, partiu-se de um diálogo inicial, de sensibilização acerca dessa atividade com a turma, posteriormente se mencionou as etapas a serem realizadas no decorrer da oficina, como a parte teórica abordando as utilidades da moringa na área agronômica, medicinal e industrial e a parte prática, com o uso das sementes de moringa para tratamento da água e ao final se aplicou um questionário avaliativo da oficina.

Dessa forma, no presente artigo, se apresenta o relato e estudo reflexivo sobre a experiência desenvolvida, a partir da análise das atividades realizadas em sala de aula, considerando sua relevância para a concepção de educação do campo, tendo em vista as observações das interações na ação prática e aos dados obtidos através dos questionários.

No decorrer do artigo, abordaremos a respeito do potencial didático-pedagógico do ensino sobre a moringa, partindo de uma breve revisão bibliográfica dos estudos que tratam dessa planta, tratando a seguir sobre a educação no campo e a prática social e na sequência fazendo uma análise reflexiva sobre a experiência da aplicação dessa oficina, abordando os aspectos relevantes para a formação profissional em agrárias.

\footnotetext{
${ }^{1}$ Não se trata aqui de tão somente a presença das várias áreas do saber científico, mas a articulação entre elas na produção de conhecimento. 


\section{REVISÃO TEÓRICA}

Uma educação contextualizada é aquela que conduz o alunado a compreensão da realidade a partir dos assuntos conceituais. Quanto mais vinculada ao que Saviani (2012) denomina de prática social maior a possibilidade de transformar o real concreto. Daí o papel transformador da sociedade através da educação. A prática social é tanto o ponto de partida quanto de chegada. No entanto, há uma alteração qualitativa na concepção de um dado conteúdo do início em relação ao fim de uma atividade escolar, o que depende muito de uma mediação da ação pedagógica intencional, crítico-reflexiva e social. Segundo Saviani (2012),

É preciso, no entanto, ressalvar que a alteração objetiva da prática só pode dar-se a partir da nossa condição de agentes sociais ativos, reais. A educação, portanto, não transforma de modo direto e imediato e sim de modo indireto e mediato, isto é, agindo sobre os sujeitos da prática. (SAVIANI, 2012)

Assim, uma breve revisão de bibliografia sobre a moringa oleífera se faz necessária para demonstrar o potencial didático-pedagógico do ensino desse conteúdo, bem como sua suscetibilidade de transformação da realidade, especialmente na abordagem da educação do campo. Essa parte teórica empregada a seguir corresponde a uma parte do conteúdo teórico explorado na oficina pedagógica.

\section{A moringa oleífera e sua vasta aplicação}

A Moringa oleífera pertence à família Moringaceae, nativa do norte da Índia, a mesma se desenvolve em vários países dos trópicos; seu fruto é uma espécie de vagem com três faces e possui um grande número de sementes (PATERNIANI et al., 2009). Segundo Bezerra et al. (1999), a moringa é uma espécie perene originária do noroeste indiano, que se adapta tanto às condições irrigadas quanto às de sequeiro, pouco exigente em solos e fertilizantes, encontra-se disseminada na região nordeste do Brasil, graças à sua utilização na clarificação de águas turvas. Sendo assim, a moringa é de grande utilidade principalmente para a população nordestina, pois é de fácil adaptabilidade e traz benefícios diversos.

De acordo com Rangel (1999), inicialmente no Brasil, a moringa começou a ser plantada e utilizada como planta ornamental. A região nordeste é mencionada na literatura como ideal para o plantio desta espécie, pelas condições do solo e do clima. A sua utilização varia desde o uso agronômico, medicinal, industrial e alimentício. No setor agropecuário, a planta é utilizada como suplemento alimentar para os animais sendo ofertada como forragem ou em forma de silagem e também na alimentação de abelhas, que são importantes agentes polinizadores. Em concordância com Jahn et al. (1986), a moringa tem diversos usos na agricultura, talvez o mais comum deles seja o uso como sebes, servindo como cerca viva ou quebra-vento. Por se tratar de uma árvore de produção rápida e com um crescimento acelerado após a poda.

As diversas formas de utilização da planta vêm fazendo com que cada vez mais os extensionistas e pesquisadores da área sejam atraídos pela moringa, já que a variedade de produtos que podem ser obtidos e a quantidade de uso dessas plantas vêm favorecer e desenvolver ainda mais o cenário rural, principalmente se tratando de agricultura familiar. Segundo Rangel (1999) as folhas de moringa podem ser utilizadas como um dos componentes da dieta na alimentação de animais. Isso mostra a diversidade do uso da planta e o seu alto potencial nutricional, sendo de grande relevância no setor agropecuário. 
Outra importante utilidade da moringa está nas suas sementes, empregadas para promover a purificação das águas para o consumo humano por meio da coagulação-floculação. O método utilizado consiste em colocar em um recipiente água bruta em contato com 2 a 3 sementes em pó de moringa por cada litro de água, dependendo da turvação desta. Após 2 horas de permanência é retirado o sobrenadante, e este é utilizado para consumo (MENDES et al., 2007). Dessa maneira, atividade da moringa oleífera como coagulante se deve ao fato de as proteínas catiônicas presentes na composição da sua semente serem solúveis em água e em contato com as partículas de carga negativa atuarem, principalmente, pelo mecanismo de adsorção e neutralização de cargas (CARDOSO et al., 2008).

Assim, no tratamento por coagulação-floculação de águas residuais ou destinadas ao consumo humano, estudos demonstram que a percentagem de remoção de turvação utilizando tanto a semente como o extrato aquoso da moringa oleífera é de 80 a 99\% (OKUDA et al., 1999). Outro aspecto positivo no uso das sementes é que o pH e o gosto da água não se modificam, o que torna a mesma palatável (AMARAL et al., 2006).

A moringa é considerada uma fonte excepcional de vitamina $A$, vitaminas $B$ e $C$, sendo o alto teor de proteínas provindo de suas folhas, galhos e do óleo de suas sementes, além disso, poucas partes da árvore contêm quaisquer toxinas possibilitando a utilização de quase toda sua extensão. Assim, é possível seu uso na alimentação humana e animal, no tratamento de água, na produção de biodiesel, na indústria cosmética, farmacêutica e na medicina (OLSON et al., 2011).

Segundo Moura et al. (2009) altos teores de carotenoides, proteínas e carboidratos foram detectados na folha in natura de moringa oleífera, como também, altas concentrações de vitamina C nas flores e vagens, o que lhes confere propriedades antioxidativas. Além disso, é viável na produção de concentrados proteicos à base de suas folhas, para posterior adição a diversos alimentos habituais como massas e cereais, o que aumentaria o valor proteico destes alimentos.

A moringa oleífera possui características que viabilizam seu uso no fornecimento de suplementação de nutrientes que se busca na alimentação sendo, portanto, possível para utilização na fortificação alimentar, como um fator redutor da situação de desnutrição (BRITO et al., 2009).

Em alguns estudos etnobotânicos constata-se que um dos principais usos conferidos à M. oleífera é o seu uso na medicina tradicional para o tratamento de diferentes sintomas e doenças. A mesma cita que na Guatemala as folhas de moringa são usadas em feridas e infecções de pele; em outras regiões se usa no combate de anemia, ansiedade, asma, bronquite, congestão no peito, tosse, diarreia, entre várias outras enfermidades. A moringa oleífera possui atividade antidiabética, pois seu extrato aquoso de folhas demonstra controlar a diabetes e exibe controlo glicémico. Além disso, possui atividade cicatrizante: o extrato aquoso das folhas foi utilizado na cicatrização de feridas e concluiu-se que o extrato possui propriedades de cicatrização significativas (MARQUES, 2018).

Com tanta aplicação na realidade concreta, estudar sobre a moringa possibilita a articulação entre os diferentes componentes curriculares como a biologia, a química, a geografia e a história, dentre outras, além de possibilitar situações didáticas para o aprimoramento de competências e habilidades. Em se 
tratando de educação do campo a realidade do alunado é mobilizada no sentido de empregar tais conhecimentos em favor da melhoria econômica do cotidiano de suas comunidades.

\section{A educação do campo e a transformação da realidade}

Até meados do século XX o Brasil ainda era um país predominantemente agrário, embora na atualidade não se possa afirmar que o suposto desenvolvimento industrial seja homogêneo considerando a dimensão continental do país. Não obstante, foi a necessidade de abastecer o sistema produtivo que mobilizou as políticas na área da educação, sendo que somente nas últimas décadas, na redemocratização brasileira, resultados das lutas e conquistas dos movimentos sociais, que se acentuaram as preocupações específicas para a educação do campo.

Falar dessa modalidade de ensino se remete a um cenário de conflitos que envolve desde a conquista do acesso à terra, a reforma agrária, a agricultura familiar, até as reinvindicações por políticas públicas que contemplem o campesinato em suas demandas sociais, contra elites agrárias e latifundiárias, detentores históricos de poder econômico e político, representantes do novo arranjo produtivo: a agroindústria. Entretanto, esse artigo se atém resumidamente a um pequeno recorte sobre aspecto ligado ao ensino e a aprendizagem, não havendo espaço para uma abordagem mais ampla a respeito.

Guido (2007) ressalta a importância fundamental da educação e cidadania, uma vez que a sociedade ainda carece desses fatores vitais, portanto, assim o mesmo confirma a ausência da verdadeira educação e da autêntica cidadania. Ao se considerar, em particular, o espaço rural, essa carência se torna ainda mais evidente. Com isso surgiu a necessidade da educação no campo, que se trata de uma política pública que possibilita o acesso ao direito à educação das pessoas que vivem fora do meio urbano e que necessitam ter esse direito garantido da mesma forma que é assegurado para a população urbana.

A Resolução no 4.783/2010 em seu artigo 3ำ, profere que "as Escolas do Campo são aquelas inseridas em comunidades caracterizadas pelo vínculo e trabalho com a terra, independentemente de sua localização". Complementando a LDBEN (9.394/96) que considera a educação do campo àquela que ocorre nas instituições escolares situadas na área rural.

Para Morigi (2003), a educação do campo deve ser aquela que assume a identidade do meio rural, comprometida com um projeto político-pedagógico voltado às causas, desafios, sonhos, história e cultura dos que vivem e atuam no campo. Dessa forma, é importante que essa educação se coloque na luta pelos direitos ao saber, ao conhecimento, à cultura produzida socialmente. Arroyo et al. (2004) consideram a educação como direito do homem, da mulher, da criança e do jovem do campo.

Sendo assim, a escola é o espaço de formação social e política dos sujeitos, ao mesmo tempo, que está possui como função social a socialização dos saberes acumulados e os processos de reelaboração e produção dos conhecimentos pelos homens ao longo dos tempos. Portanto, para àqueles que vivem no campo, é também um espaço de luta e resistência, logo, de emancipação. Deste modo, uma educação escolar ligada ao trabalho e às práticas sociais é um campo fértil para a transformação da realidade. 


\section{METODOLOGIA}

Foi empregado como elemento metodológico para a execução das análises da experiência a aplicação da oficina intitulada "As diferentes utilidades da moringa oleífera", as observações participativas dos sujeitos envolvidos e um questionário. De acordo com Paviani et al. (2009) numa oficina ocorre apropriação, construção e produção de conhecimentos teóricos e práticos, de forma ativa e reflexiva. É, pois, uma oportunidade de vivenciar situações concretas e significativas.

As oficinas são capazes de proporcionar aprendizagens mais completas, pois valoriza a construção do conhecimento de forma participativa e questionadora, baseada em situações do cotidiano do aluno (NASCIMENTO, 2007). Assim sendo, os aspectos teóricos ganham forma na articulação com a prática executada nessas atividades, favorecendo à compreensão concreta do real a partir da aprendizagem construída.

A oficina pedagógica ocorreu em dois momentos: com uma exposição dialógica sobre a planta com abordagem conceitual, contextualizada e interdisciplinar; e com a aplicação do tratamento de água a partir de sementes da moringa, além de outras atividades teórico-práticas a serem descritas a seguir. No final das atividades os alunos responderam a um questionário para avaliação da aprendizagem e da oficina.

\section{RESULTADOS E DISCUSSÃO}

\section{Desenvolvimento da oficina: planejamento e execução}

O processo de realização da oficina teve início com a aquisição de sementes da moringa na qual é encontrada facilmente na região. Após isso, foram realizadas pesquisas bibliográficas referentes aos diversos usos da planta nos setores agronômico, medicinal, industrial e alimentício. Depois foram selecionados os conteúdos, planejado a realização da oficina e elaborado o questionário avaliativo.

No dia da aplicação da oficina foi explanado aos alunos participantes sobre as diferentes utilidades da moringa em diversas áreas como: agronômico, no qual se mostrou o potencial de utilização da mesma na alimentação animal, para tanto foi apresentada partes integrantes da planta como folhas e talos triturados, exemplificando como pode ser servido para suplementação alimentar dos animais. Foi mostrada também a substituição das rações convencionais por rações que tem como base a moringa, exemplificou-se essa prática na ração de galinhas caipiras. Essa substituição das rações convencionais reduz significativamente os gastos do pequeno produtor rural, que passa a investir menos em rações que tem como base milho e sorgo, e são de custo alto; assim o pequeno produtor passa a investir menos, utilizando produtos que podem ser obtidos na sua propriedade e consequentemente aumentando seus lucros. No seu uso medicinal foi mostrado o aproveitamento das sementes para purificação da água, o que é de grande valia tendo em vista o grande número de pessoas sem acesso a água tratada; nessa etapa os alunos foram convidados para participarem da parte prática da oficina, na qual se orientou em como fazer para que a semente possa contribuir na purificação da água.

Para isso, levou-se um vaso com água turva para o desenvolvimento da prática com os educandos. 0 
passo a passo do beneficiamento da semente da moringa para purificação da água se inicia em amassar as sementes, sendo necessárias apenas três sementes para cada litro de água. O pó dessas sementes age efetuando a limpeza da água, fazendo com que todas as impurezas, resíduos sólidos, e outros sejam decantados, tornando a água propicia ao consumo humano, conforme se demonstra nas imagens abaixo.

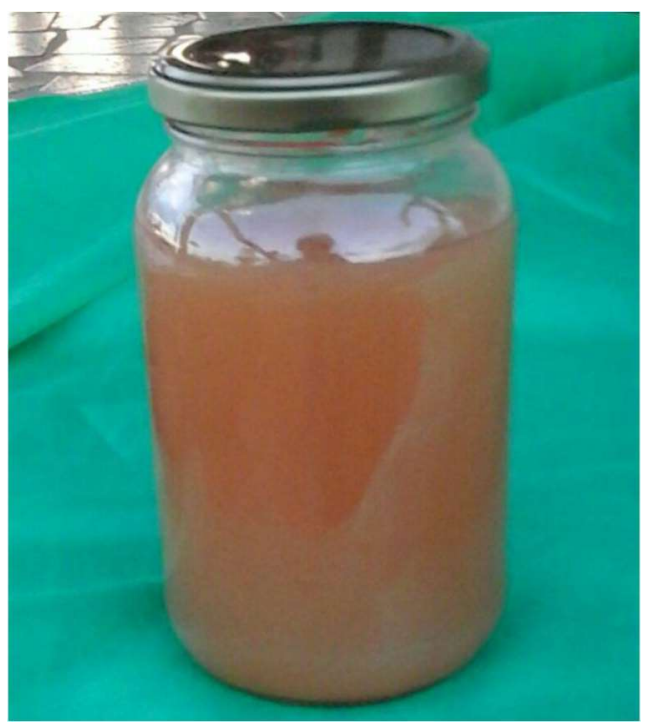

Imagem 1: Água turva, sem o uso da sementes da moringa.

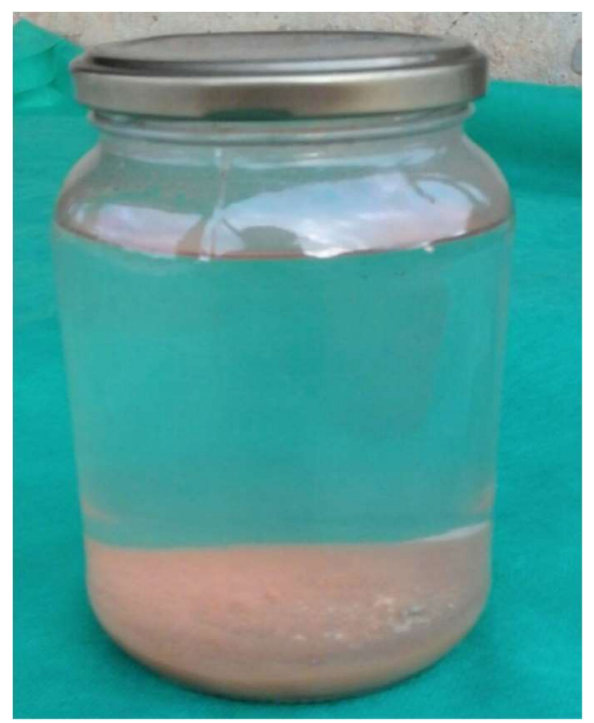

Imagem 2: Água após o uso das sementes da moringa.

Através da análise das imagens acima é possível evidenciar o contraste entre a água antes do uso das sementes da moringa e a água após o uso do pó das sementes, ressaltando o quanto que o emprego das sementes contribui no tratamento das águas e é uma alternativa verídica e possível para a população campesina. Esse ponto em questão foi bastante frisado, pois é sabido da importância de se preservar alternativas viáveis para o tratamento da água, principalmente para aqueles que vivem em regiões de grande escassez de água e de vulnerabilidade social, sem acesso a água de qualidade. No mesmo seguimento vem à alimentação humana em que a moringa também é muito importante, pois é possível aproveita-la em diversos pratos da culinária como, por exemplo: saladas, patês, arroz, chás e outros.

Sendo assim, foi relatado para os participantes da oficina o processo de como se faz o chá da moringa e seus efeitos medicinais, e posteriormente foi servido para aqueles que desejassem experimentar. $\mathrm{E}$ também mencionamos o potencial de uso da moringa para o setor industrial, no qual já acontece a fabricação de muitos produtos à base do óleo da moringa; foram mostrados alguns produtos que são fabricados a partir de partes da moringa, como: cremes feitos das folhas, óleo extraído das sementes que serve para produção de cosméticos e o biodiesel, evidenciando assim os benefícios do uso da moringa e a variedade de produtos que podem ser produzidos a partir dessa planta. Salientando, ainda, o uso destes produtos para tratamentos de beleza e saúde.

Ao final da oficina foi entregue aos alunos um questionário a respeito do desenvolvimento geral da oficina, onde os mesmos tiveram que responder se já tinham conhecimento sobre as diferentes possibilidades de uso da moringa; se diante do que foi exposto eles consideravam viável o uso da moringa em suas comunidades; tendo em vista o valor nutricional da planta, se utilizariam no consumo humano; e se 
são encontrados exemplares dessa planta na localidade em que eles vivem. Além disso, foram distribuídos saquinhos com sementes de moringa com o intuito de propagação da moringa na região, e posteriormente, foi exemplificado como fazer um recipiente de baixo custo para germinação das sementes, onde se utilizou papel e um copo para ser usado como molde. Sendo um método simples, não necessitando retirar o papel para fazer o transplante da muda para o solo, pois o mesmo é de rápida decomposição no ambiente.

Assim, o desenvolvimento da oficina mostrou-se um importante contribuinte na aquisição de conhecimentos, por meio de saberes historicamente construídos e da experiência na prática, tanto para aqueles que aplicaram a atividade, quanto para os que participaram da mesma, por se tratar de um assunto que abrange a área que tais indivíduos estão inseridos. Além de contextual, vinculado ao mundo do trabalho, o conteúdo foi abordado em articulação com outras áreas do conhecimento, isto é, de maneira interdisciplinar, podendo alcançar o contexto dos discentes com uma prática social emancipatório que incida sobre seus cotidianos.

Foi perceptível que a grande maioria dos participantes da oficina não tinha conhecimento a respeito das diversas utilidades da moringa e que ficaram curiosos em aprender sobre determinado assunto. Essa afirmação pode ser comprovada através do questionário que foi aplicado ao final da oficina, onde mais de $90 \%$ dos alunos disseram que não conheciam os tais potenciais usos dessa planta.

Por meio das respostas do questionário também foi possível evidenciar que a maioria dos alunos tenderam a alteração qualitativa sobre suas práticas sociais uma vez que consideraram viável o uso da moringa oleífera nos diversos setores apresentados. Assim, fica nítido que houve aproveitamento dos participantes da oficina em relação às informações esplanadas com grande potencial de transformação da realidade, uma vez que a oficina criou as condições para o uso dessa planta em suas comunidades.

\section{CONCLUSÕES}

A realização deste trabalho foi uma grande oportunidade para aquisição de conhecimentos aos futuros profissionais na área das ciências agrárias, tanto aos que aplicaram quanto aos que foram contemplados com a oficina pedagógica. Aos primeiros se permitiu uma aproximação com a realidade da ambiente sala de aula e uma troca de experiências entre os sujeitos participantes, e aos segundos proporcionou o acesso aos saberes científicos de cunho técnico e social com potencial de implicações no concreto real das localidades onde residem.

A aquisição dos conhecimentos sobre o uso da planta é de suma importância devido a todos os seus potenciais, levando em consideração as necessidades que assolam o homem do campo e sua comunidade. Portanto, a escola tem papel fundamental no processo de construção da cidadania e da democracia. Sendo de grande importância o desenvolvimento de trabalhos com atividades práticas e dinâmicas para que o ensino técnico esteja qualificado em frente às funções fundamentais da educação quanto ao aspecto humano, do mercado de trabalho e da cidadania.

Diante disso, é importante salientar o apoio da direção e professores do CETEP para a execução dessa atividade com os alunos, que mostraram interesse em compartilhar tais informações com outras turmas da 
escola, podendo assim socializar tais conhecimentos para outras comunidades, ampliando assim o potencial transformador da realidade.

No decorrer do desenvolvimento da oficina os objetivos projetados foram alcançados, tendo em vista a interação e a participação dos alunos. Desse modo, a aplicação dessa oficina contribuiu para a efetivação de um ensino contextualizado, interdisciplinar, emancipatório, vinculado aos aspectos do mundo do trabalho e das práticas sociais, pautado na demanda de uma verdadeira educação do campo, através da disseminação de conhecimentos sobre a moringa oleífera.

Ressalta-se especialmente o valor didático-pedagógico dessa atividade para todos os alunos que participaram, no qual demonstraram interesse em compartilhar os saberes adquiridos sobre as utilidades da moringa, cooperando assim com sua comunidade, para que haja uma melhoria da qualidade de vida dos pequenos produtores rurais da região.

\section{REFERÊNCIAS}

AMARAL, L. A.; ROSSI JÚNIOR, O. D.; SOARES E BARROS, L. S.; LORENZON, C. S.; NUNES, A. P.. Tratamento alternativo da água utilizando extrato de semente de Moringa oleífera e radiação solar. Arquivos do Instituto Biológico, v.73, n.3, p.287-293, 2006.

ARROYO, M. G.; CALDART, R. S.; MOLINA, M. C.. Por uma educação do campo. Petrópolis: Vozes, 2004.

BEZERRA, A. M. E.; ALCONFÔR, D. C.; MEDEIROS FILHO, S.; INNECCO, R.. Germinação de sementes de moringa (Moringa Oleífera Lam). Ciência Agronômica, Fortaleza, v.28, n.1/2, 1999.

BRITO, T. M. L. P.; TEIXEIRA, E. M. B.. Aceitabilidade do pão francês enriquecido com pó da folha da Moringa oleífera lam. In: ENCONTRO NACIONAL DE MORINGA. Anais. Aracaju, 2009. p.1-5.

CARDOSO, K. C.; BERGAMASCO, R.; COSSICH, E. S.; MORAES, L. C. K.. Otimização dos tempos de mistura e decantação no processo de coagulação/floculação da água bruta por meio da Moringa oleífera Lam. Acta Sci. Tech., v.30, n.2, p.193198,2008

GUIDO, H.. Filosofia da Educação: entre o anti-moderno e o ultra-moderno. In: HENZ, C. I.; ROSSATO, R.. Educação humanizadora na sociedade globalizada. Santa Maria: Biblos, 2007.

JAHN, S. A. A.; MUSNA, H. A.; BURGSTALLER, H.. The tree that purifies water: cultivating multipurpose Moringacea. Sudan Unasylva, v.38, p.23-28, 1996.

MARQUES, M. S. A.. Moringa oleífera Lam., seus benefícios medicinais, nutricionais e avaliação de toxicidade. Dissertação (Mestrado) - Faculdade de Farmácia da Universidade de Coimbra, Coimbra, 2018.
MENDES, F.; COELHO, N.. Estudo do uso da Moringa oleífera para remoção de prata e manganês em águas. Uberlândia: Horizonte Científico, 2007.

MORIGI, V.. A escola do MST: uma utopia em construção. Porto Alegre: Mediação, 2003.

MOURA, A. S.; SOUZA, A. L. G.; JUNIOR, A. M. O.; LIRA, M. L.; SILVA, G. F.. Caracterização físico-química da folha, flor e vagem da moringa (Moringa oleífera Lamarck). In: ENCONTRO NACIONAL DA MORINGA Anais. Aracaju, 2009.

NASCIMENTO, M. S.. Oficinas pedagógicas: Construindo estratégias para a ação docente: relato de experiência. Rev. Saúde Com., v.3, n.1, p.8595, 2007.

OLSON, M. E.; FAHEY, J. W.. Moringa oleífera: un árbol multiusos para las zonas tropicales secas. Rev. Mex. Biodiv. Cidade do México, v.82, n.4, p.1071-1082, 2011.

OKUDA, T.; BAES, A.; NISHIJIMA, W.; OKUDA, M. Improvement of extraction method of coagulation active components from Moringa oleifera seed. Water Research, v.33, n.15, 1999.

PATERNIANI, J. E. S.; MANTOVANI, M. C.; SANT'ANNA, M. R. Uso de sementes de Moringa oleífera para tratamento de águas superficiais. Revista Brasileira de Engenharia Agrícola e Ambiental, Campina Grande, v.13, n.6, p.765-771, 2009.

PAVIANI, N. M. S.; FONTANA, N. M.. Oficinas pedagógicas: relato de uma experiência. Conjectura, Caxias do Sul, v.14, n.2, p.77-88, 2009.

RANGEL, M. S. A.. Moringa oleífera: uma planta de uso múltiplo. Aracaju: Embrapa Tabuleiros Costeiros, 1999.

SAVIANI, D.. Escola e Democracia. 42 ed. Campinas: Autores Associados, 2012.

A CBPC - Companhia Brasileira de Produção Científica (CNPJ: 11.221.422/0001-03) detém os direitos materiais desta publicação. Os direitos referem-se à publicação do trabalho em qualquer parte do mundo, incluindo os direitos às renovações, expansões e disseminações da contribuição, bem como outros direitos subsidiários. Todos os trabalhos publicados eletronicamente poderão posteriormente ser publicados em coletâneas impressas sob coordenação da Sustenere Publishing, da Companhia Brasileira de Produção Científica e seus parceiros autorizados. Os (as) autores (as) preservam os direitos autorais, mas não têm permissão para a publicação da contribuição em outro meio, impresso ou digital, em português ou em tradução. 